Volume 2, Nomor 1 (Mei 2017)

ISSN 2477-2399 (online)

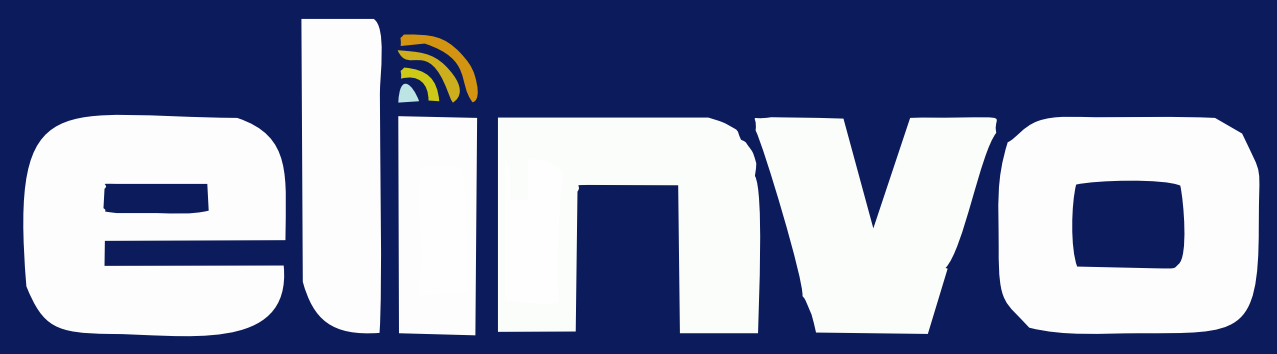

(Electronics, Informatics, and Vocational Education) 


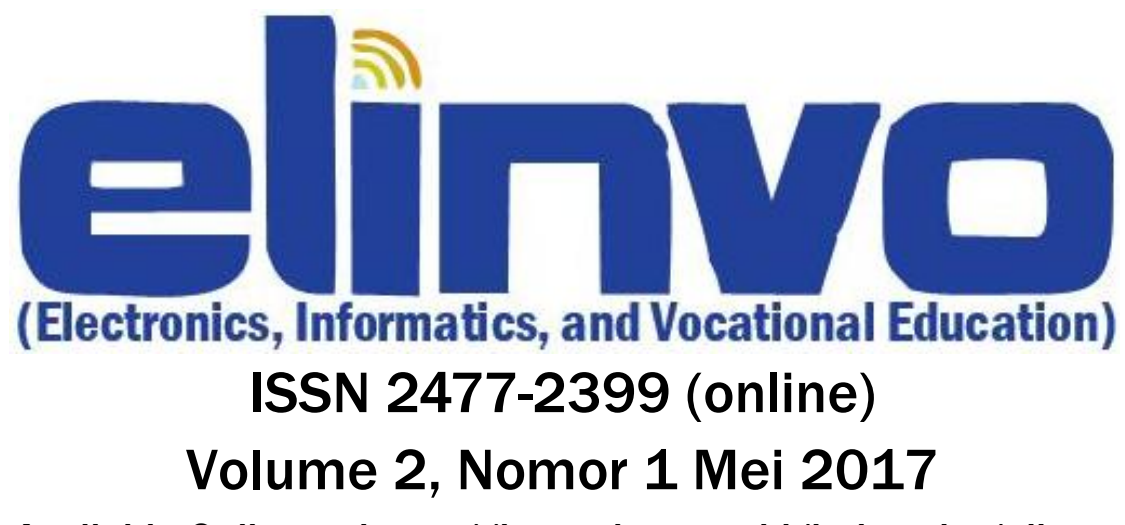

Available Online at https://journal.uny.ac.id/index.php/elinvo

\title{
Editorial Arrangement
}

\author{
Editor in Chief \\ Handaru Jati \\ Editorial Board \\ Fatchul Arifin \\ Suprapto \\ Assistant Editor \\ Pipit Utami \\ Bekti Wulandari \\ Bonita Destiana \\ Peer Reviewers \\ Herman Dwi Surjono \\ Putu Sudira \\ Masduki Zakaria \\ Nurkhamid \\ Djoko Santoso \\ Muh. Munir
}

\section{Administration}

Vita Wahyu Insanigati

\section{Published By}

Jurusan Pendidikan Teknik Elektronika Fakultas Teknik Universitas Negeri Yogyakarta

\section{Editorial Address}

Kompleks Fakultas Teknik Kampus Karangmalang, Yogyakarta, 55281, (0274) 554686. Website: http://journal.uny.ac.id/index.php/elinvo Email: elinvo@uny.ac.id

ELINVO (Electronics, Informatics and Vocational Education) merupakan jurnal yang terbit dua kali dalam setahun. Jurnal ini merupakan media publikasi berisi tulisan yang diangkat dari hasil penelitian atau telaah kajian di bidang elektronika dan informatika ditinjau dari perkembangan teknologi atau dari perkembangan pengajarannya serta bidang pendidikan vokasi. 


\section{PREFACE: From the Editors}

Alhamdulillah kami panjatkan kepada Alloh swt. yang telah melimpahkan kelancaran atas terbitnya ELINVO (Electronics, Informatics and Vocational Education) Volume 1, Nomor 1 (Mei 2017). ELINVO (Electronics, Informatics and Vocational Education) diterbitkan oleh Jurusan Pendidikan Teknik Elektronika Fakultas Teknik Universitas Negeri Yogyakarta.

Pada nomor ini disajikan tiga belas artikel berkualitas bidang elektronika, bidang informatika dan bidang pendidikan vokasional. Terimakasih kami ucapkan kepada para penulis yang telah berhasil mempublikasikan artikelnya pada ELINVO (Electronics, Informatics and Vocational Education) dan kepada para reviewer, layouter, editor dan pihak lainnya yang telah memberikan kontribusi atas terbitnya ELINVO (Electronics, Informatics and Vocational Education) Volume 1, Nomor 1 (Mei 2017).

Besar harapan kami, ELINVO (Electronics, Informatics and Vocational Education) dapat memberikan kontribusi bagi pengembangan teknologi dan pendidikan vokasi khususnya di bidang elektronika dan informatika. Kami menerima saran-kritik, tanggapan dan kontribusi positif bagi pengembangan ELINVO (Electronics, Informatics and Vocational Education) dari para kontributor kami harapkan dapat meningkatkan kualitas ELINVO. Untuk info terkait alur penerbitan artikel di ELINVO (Electronics, Informatics and Vocational Education) untuk edisi berikutnya Volume 2 Nomor 2 (November 2017) mohon anda dapat mengakses membuka http://journal.uny.ac.id/index.php/elinvo. Semua artikel yang diterbitkan tersedia secara online.

Yogyakarta, Mei 2017 


\section{TABLE OF CONTENTS}

Editorial Arrangement li

Preface: From the Editors lii

Table of Contents IV

ANALISIS PRINSIP LAYOUT AND COMPOSITION PADA WEB DESIGN

PERUSAHAAN PT. BANK RAKYAT INDONESIA, TBK DAN PT. FIF GROUP

BERDASARKAN BUKU "THE PRINCIPLE OF BEAUTIFULL WEBSITE DESIGN (2ND EDITION) BY JASON BEAIRD"

Heri Kuswanto

ANALISIS DESAIN WEBSITE BNI, BUKOPIN, J.CO DONUTS DAN MCDONALS MENURUT BUKU "THE PRINCIPLES OF BEAUTIFUL WEB DESIGN"

Fitria Ekarini

PENERAPAN DATA MINING MENGGUNAKAN PERBANDINGAN ALGORITMA

21-26

GREEDY DENGAN ALGORITMA GENETIKA PADA PREDIKSI RENTET WAKTU

8-20

HARGA CRUDE PALM OIL

Desy Ika Puspitasari

TRAINER PID CONTROLLER SEBAGAI MEDIA PEMBELAJARAN PRAKTIK

$27-40$

SISTEM KENDALI

Eko Marpanaji, Bekti Wulandari, Muhammad Izzudin Mahali,\& Nuryake

Fajaryati

SISTEM TEKANAN MEKANIK BERBASIS MIKROKONTROLER AT-MEGA 16

41-48

UNTUK PEMBUATAN KERUPUK PELOMPONG GUNA MENUNJANG

PRODUKSI HOME INDUSTRY BAROKAH DI TUBAN JAWA TIMUR

Adibatul Ardianto \& Dessy Irmawati

E-LEARNING BERBASIS SCHOOLOGY DAN EDMODO: DITINJAU DARI

$49-58$

MOTIVASI DAN HASIL BELAJAR SISWA SMK

Agus Efendi

ANALISIS KEBERHASILAN SISTEM E-LEARNING SMK NEGERI 1 MALANG

Intan Sulistyaningrum Sakkinah \& Syaad Patmanthara

RANCANG BANGUN APLIKASI E-REPORT PENGADUAN MASYARAKAT

64-73

DESIGN PUBLIC COMPLAINT E-REPORT APPLICATION

Roviana H. Dai, Lillyan Hadjaratie \& Nuzran Firmansyah Bouti

THE DESIGN AND IMPLEMENTATION OF AN EDUCATIONAL MULTIMEDIA

74-79 INTERACTIVE OPERATION SYSTEM USING LECTORA INSPIRE

Setya Chendra Wibawa, Rina Harimurti, Yeni Anistyasari \& Meini Sondang Sumbawati 
ANALISIS APLIKASI JADWAL PERKULIAHAN BERBASIS ANDROID

Daniswara Galuh Sukmandari \& Totok Sukardiyono

PENGEMBANGAN SISTEM INFORMASI MANAJEMEN PRAKTIK INDUSTRI DI

85-93

JURUSAN PENDIDIKAN TEKNIK ELKTRONIKA UNY BERBASIS WEBSITE

MENGGUNAKAN YII FRAMEWORK

Agung Rizki Subhan \& Handaru Jati

ANALISIS KUALITAS SISTEM INFORMASI KEGIATAN SEKOLAH BERBASIS

94-101

MOBILE WEB DI SMK NEGERI 2 YOGYAKARTA

Taufiq Abdul Ghaffur \& Nurkhamid

ANALISIS KUALITAS SISTEM INFORMASI PANTAUAN PEMBENTUKAN

102-109

KARAKTER SISWA DI SMK N 2 DEPOK SLEMAN

Heru Setiawan \& Handaru Jati

Guidelines for Author

Publication Ethics 